Unfortunately the taxonomy employed by the author is in places outda ted, revealing a tendency to ignore the results of recent researchers and adhere to Ellerman and Morrison Scott's Palaearctic Checklist, compiled more than 25 years ago (e.g. Eptesicus isabellinus page 66). At times too the author seems not to understand the fundamental rules of zoological nomenclature-how can Allactaga euphratica, properly named in 1881, possibly be a 'synonym' (page 245) of Allactaga williamsi, named in 1897 ? In fact the latter is a valid subspecies of the former.

However, these are but minor criticisms of a work which will be immensely valuable to all in the field of mammalogy for many years to come. It will be greatly treasured in this reviewer's bookcase and both the author and publishers are to be congratulated on a first class production. The price may be high, but no true student of mammalogy can afford to be without it.

DAVID L. HARRISON

\title{
The Scientific Results of the Oman Flora and Fauna Survey 1975. Journal of Oman Studies, Special Report. Michael Rice, 1 Lowther Gardens, Prince Consort Rd, London SW7 2AA, O. rupees 5; US \$10.
}

One could wish that all the leaders of developing countries would think as the Sultan of Oman writes in his excellent foreword to this book: 'Through rapid development, terrible mistakes have been made in the world. All development should be directed towards the rational use of the world's resources to obtain the best possible quality of living ... Conservation goes hand-in-hand with development to achieve this goal'. The Sultan's support and assistance made possible the 1975 survey of the plants and animals of the area containing the Jabal Akhdar National Park, in the mountains of Oman, and this report on the survey is the basic material for conservation in Oman as well as a valuable reference work for everybody interested in deserts. It is carefully documented, well written and illustrated and beautifully produced - a pleasure to handle. It is the first reasonably comprehensive study of the 10,000 ft Jabal Akhdar massif, which has water, trees and habitations above $6000 \mathrm{ft}$, and the report covers mammals, birds, reptiles and amphibia, freshwater fishes, butterflies and moths, scorpions, molluscs and plants, with a brief account of ectoparasites from mammals. There is nothing on beetles.

The expedition consisted of five naturalists led by David Harrison, who opens with a description of the 59 mammal species obtained, and a checklist of Oman mammals. It lasted a mere month and was forced to concentrate on collecting and listing, but the report goes well beyond that. Thus, M. D. Gallagher's ornithological account includes background material on history, climate, geology and landform and the zoogeographical aspects of the region's birds. It includes, also, a checklist covering all records for the area. Of the 71 species recorded, 40 were for the first time. The area is of course a crossroads for migrants, and 41 species were on passage. Bonelli's eagle is believed to breed on the jabal and the short-toed eagle may breed further west. There is some challenge to the idea that the desert steppes of Arabia form a serious barrier to northerly movement from Ethiopia. Major Gallagher was obviously a tower of strength, for he collected mammals, reptiles, molluscs and lepidoptera as well as birds.

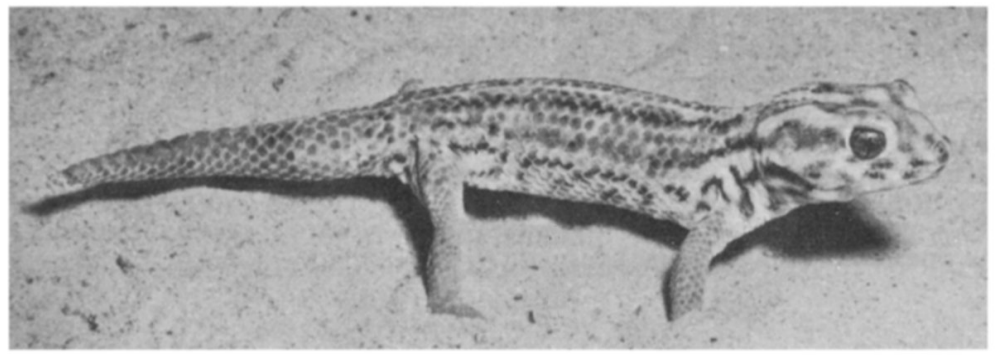

Teratoscincus scincus. This photograph by $\mathrm{E} . \mathrm{N}$. Arnold, taken in 1976 , was the first record of this skink in Arabia. Reproduced from the Oman Survey Report. British Museum (N.H.) 
The reptiles and amphibia (Arnold and Gallagher) are listed and discussed, and many entries under species contain interesting notes on behaviour. Affinities are also discussed. The geckoes (E. N. Arnold) form an important element of the fauna $(30 \%$ of all terrestrial reptiles and probably at least 29 species). The morphology and distribution of the freshwater fishes, are described and illustrated by K. E. Banister and M. A. Clarke, the lepidoptera fully described by E. P. Wiltshire, T. B. Larsen contributes a gorgeously illustrated section on the butterflies of Eastern Oman. M. Vachon describes (in French) the three species of scorpions (but no spiders) and K. R. Smythe and M. D. Gallagher ten species of land and freshwater molluscs. The section on plants (J. P. Mandville), a valuable general introduction to the area and the history of its botanical exploration, is organised in zones (desert parkland, mountain wadis, steep rock slopes etc.) and concludes with a systematic list of all plants collected. And there are some memorable colour photographs.

J. B. NELSON

Les Oiseaux du Zaire, by Leon Lippens and Henri Wille. Editions Lannoo, Tielt, Belgium, Frs. belg. 3000 .

'On ne peut protéger que ce qu'on aime et on ne peut aimer que ce qu'on connaît', writes President Mobutu in a preface to this splendid tome, which should, as the President says is its aim and purpose, make a real contribution to conservation in Zaire. It is published on his authority and with his wholehearted backing, and although produced with a lavishness more typical of a bygone age, and with a $34 \times 25-\mathrm{cm}$ format, it is fully up to date in its style and simple, direct approach. The 509 pages allow on average about a third of a page to each of the 1086 species recorded in Zaire, four of which were added during a year's field work organised for the purpose of the book in $1973 / 74$, including the remarkable discovery in the Upemba National Park of the spotted thrush Turdus fischeri, previously known from two widely separated localities - on the east coast of Africa and inland only in the extreme south of Malawi. The illustrations, which consist entirely of fully captioned colour photographs, cover 398 species; for some 160 of them two or occasionally three photographs show differences attributable to age, sex or subspecies, birds in flight, or peculiar behaviour, such as the famous symbiosis of pelicans and fishermen. For each of the 1086 species there is also a $4 \times 3.5 \mathrm{~cm}$ map, in the broad lefthand margin of every page, which may either be of Zaire, to show the distribution of the 27 endemic species (the Congo peacock being the outstanding example), or of the whole of Africa, for the majority of species, or, for more widespread or migratory species, of the appropriate segment of the globe (in which category the information tends rather naturally to be somewhat less reliable).

Within the space available, further reduced by 53 pages of introduction and indices (of the scientific and French names of the birds, only), the authors have done excellently to distil in an average of two or three hundred words, a map and, for about a third of the species, a photograph or two, such evocative and up-to-date (to 1974) accounts of all the species of the richest avifauna of any country of Europe or Africa. Inevitably, perhaps, the content and reproduction of the photographs is rather uneven; most satisfactory on the whole are those taken in their natural habitat, chiefly of larger non-passerines, and often rather distant. Several of these and also particularly the dozen or so landscape photographs illustrating the introductory chapters, are almost breathtakingly good, conveying to perfection the appearance and 'feel' of the major biotopes and their most spectacular birds.

The introductory material contains much of interest and value, including detailed analyses of endemicity in the Zairois avifauna, compared with those of other countries or sectors of the Ethiopian region, and of its origins and development in Zaire's particularly favourable environment for evolutionary change.

Cost and size will limit private ownership of this book, but it is to be hoped that it will 